\title{
New Arboreal Oribatids (Arachnida: Acari: Oribatida: Oripodidae) Collected from Broadleaf Evergreen Trees in Central Japan
}

\author{
Jun-ichi Aoki ${ }^{1}$ and Yoshinori Yamamoto ${ }^{2}$ \\ ${ }^{1}$ 3-8-12, Nishi-Azabu, Minatoku, Tokyo, 106-0031 Japan \\ E-mail:ja-muck@ma.rosenet.ne.jp \\ ${ }^{2}$ Wakayama School for the Blind, 949-23 Fuchu, Wakayama, 649-6338 Japan
}

(Received 26 May 2007; Accepted 5 November 2007)

\begin{abstract}
A new species and a new subspecies of oribatid mites, Oripoda obliqua and Truncopes moderatus variabilis, are described from Wakayama City, central Japan. These oribatids were collected by beating trees in a shrine forest. Oripoda obliqua is distinguishable from related species by its broad body, its sensilli being mostly covered, and its arched rostral margin. Truncopes moderatus variabilis differs from the nominate subspecies in its almost glabrous prodorsal surface, its humeral projections being half separated from the body outline, and its highly variable number of genital setae.

Key Words: Acari, Oribatida, Oripodidae, Oripoda, Truncopes, new species, new subspecies, Wakayama, Japan.
\end{abstract}

\section{Introduction}

The main habitat of oribatid mites is the soil, but some species are arboreal. The members of the family Oripodidae, above all, seem to prefer trees to soil as their habitat.

The junior author collected oribatids from living trees by beating, thereby obtaining two species in a shrine forest in Wakayama City, Japan. These species belong to the genera Oripoda and Truncopes of the family Oripodidae, representing a new species and a new subspecies of T. moderatus Aoki and Ohkubo, 1974, respectively. These are described and illustrated below.

The Japanese species of the family Oripodidae were revised by Aoki and Ohkubo (1974), who described one species of Oripoda and four species of Truncopes. Oripoda obliqua sp. nov. is the second species of its genus in Japan, and Truncopes moderatus variabilis subsp. nov. is an additional subspecies of Truncopes in Japan.

\section{Materials and Methods}

Arboreal oribatid mites were collected by beating tree branches. The collecting gear was designed by the junior author. A piece of square satin cloth $(70 \times 70$ $\mathrm{cm}$ ) is spread out by a pair of crossed rods. A square hole in the center of the cloth is blocked by a net that feeds into a metal funnel and polyethylene vial (Figs 1,2). 

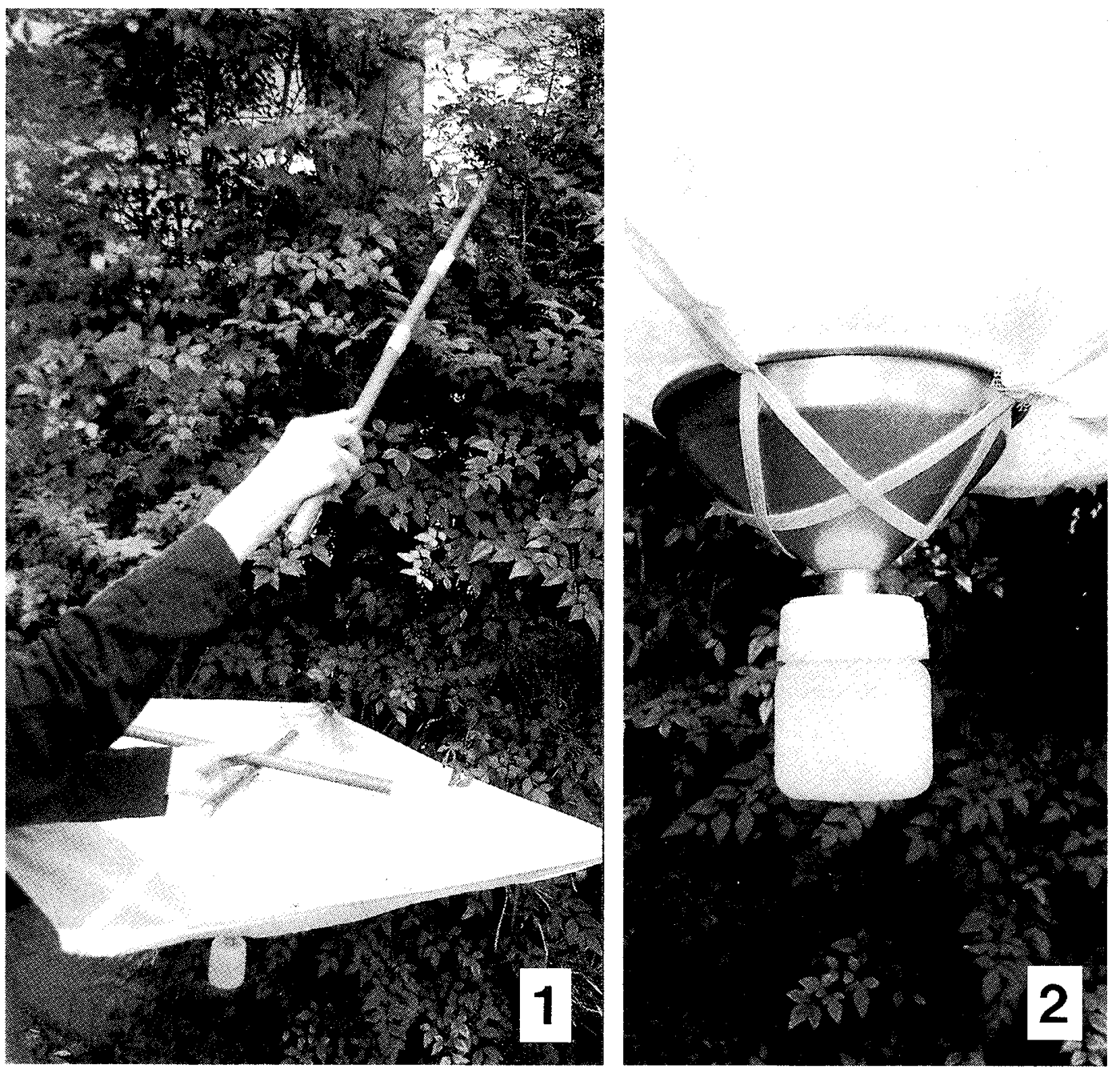

Figs 1, 2. The collecting apparatus for tree-inhabiting mites designed by Y. Yamamoto. 1, Outspread satin net and beating rod; 2 , funnel and collecting vial attached beneath the net.

Tree-inhabiting mites and other arthropods, dropping onto the cloth as the result of repeatedly beating the tree branches, are collected in the vial by flicking the slippery cloth with one's fingers. The vial containing mites is then unscrewed from the funnel, and ethanol $(80 \%)$ is poured into the vial, which is closed with another screw cap. This apparatus most closely resembles Balogh's (1958) "Klopfschirm" beating net. Arthropods preserved in ethanol were poured out into a Petri dish and oribatid mites were picked out by a pipet and mounted on glass slides with Hoyer's solution.

The type series is deposited in the collection of the National Museum of Nature and Science (NSMT), Tokyo, Japan, and the NSMT-Ac numbers cited below are the accession numbers in that museum's Acari collection. The terminology of body setae follows Balogh and Balogh (1992).

For comparison, the type material of Truncopes moderatus moderatus Aoki and Ohkubo, 1974 (holotype, NSMT-Ac 8426; and paratypes, NSMT-Ac 8427-8429) were examined. 


\section{Taxonomy}

Oripoda obliqua sp. nov.

(Figs 3-7)

Material examined. Holotype: female, NSMT-Ac 12038, Fuchu Shrine in Wakayama City, central Japan, 20 April 2007, coll. Y. Yamamoto from Quercus glauca Thunb. Paratypes: 2 males and 10 females, NSMT-Ac 12039-12046, same data as holotype; 2 males and 4 females, NSMT-Ac 12047, 12048, Fuchu Shrine in Wakayama City, central Japan, 10 May 2007, coll Y. Yamamoto from Camellia japonica L.

Measurements (in $\mu \mathrm{m}$ ). Males (3 exs): body length 305-320 (mean 313), width 178-200 (mean 188). Females (14 exs): body length 310-415 (mean 367), width 180-240 (mean 216).

Description. Rostral margin smoothly arched. Dorsal side of rostrum with irregular and short transverse ridges in females (Fig. 3), but with fine granules in males (Fig. 4). Rostral seta (ro) thin, weakly curved inward. Lamellar seta (le) thicker than ro, strongly curved inward, inserted at anterior end of slender lamella. Interlamellar seta (in) thicker than $l e$, rather blunt at tip. All prodorsal setae finely barbed and not greatly differing in length. Sensillus bearing strongly swollen, finely granulated head and short peduncle; head completely or mostly concealed under anterior expansion of notogaster. Anterior margin of notogaster nearly straight or slightly bent. Humeral part of notogaster, largely cut obliquely, without anterior projection. Ten pairs of notogastral setae rather strong; anterior setae weakly and posterior setae strongly curved; seta $\mathrm{lm}$ situated at level anterior to seta la. Anal opening $1.1-1.4 \times$ as long as and $1.4 \times$ as wide as genital opening. Interspace between anal and genital openings about twice as long as genital opening. Genital plate with 2 setae; anal plate with 2 setae, both $a n_{1}$ and $a n_{2}$ inserted distant from anal margin; surface of anal plate finely punctured. Three pairs of adanal setae; $a d_{2}$ inserted at level of mid-length of anal opening; $a d_{3}$ located in front of anterior anal margin. Mutual distance between aggenital setae nearly equal to width of genital opening.

All legs tridactyle, with all three claws similar to each other, median one only slightly thicker than lateral ones. Tarsi of legs I and II thick and short, mostly rectangular in dorsal aspect, only little longer than genua I and II; tarsus I little longer than tarsus II. On tarsus I solenidion $\omega_{1}$ curled, far shorter than weakly curved $\omega_{2}$; on tarsus II both solenidia $\omega_{1}$ and $\omega_{2}$ curled, similar in shape and length to each other. Solenidion $\phi$ on tibia I inserted on strong apophysis, but that on tibia II without apophysis. Tibiae I and II each with small spine on ventroproximal part.

Remarks. One of the important characters for discriminating the species of Oripoda is the shape of the humeral parts of the notogaster. The thirty-three known species of Oripoda listed in Subias (2004) are divided into two groups. The new species belongs to the species group with the humeral parts of notogaster largely cut obliquely, with neither a rectangular expansion nor an anterior projection. The following known species are included in this group: Oripoda angolensis Balogh, 1963, O. anguina (Balogh and Mahunka, 1969), O. divergens (Balogh and Mahunka, 1969), O. magna (Balogh and Mahunka, 1969), O. canagartnami (Balogh, 1970), O. cubana (Balogh and Mahunka, 1980), O. sumonyii Mahunka, 1985 and $O$. 


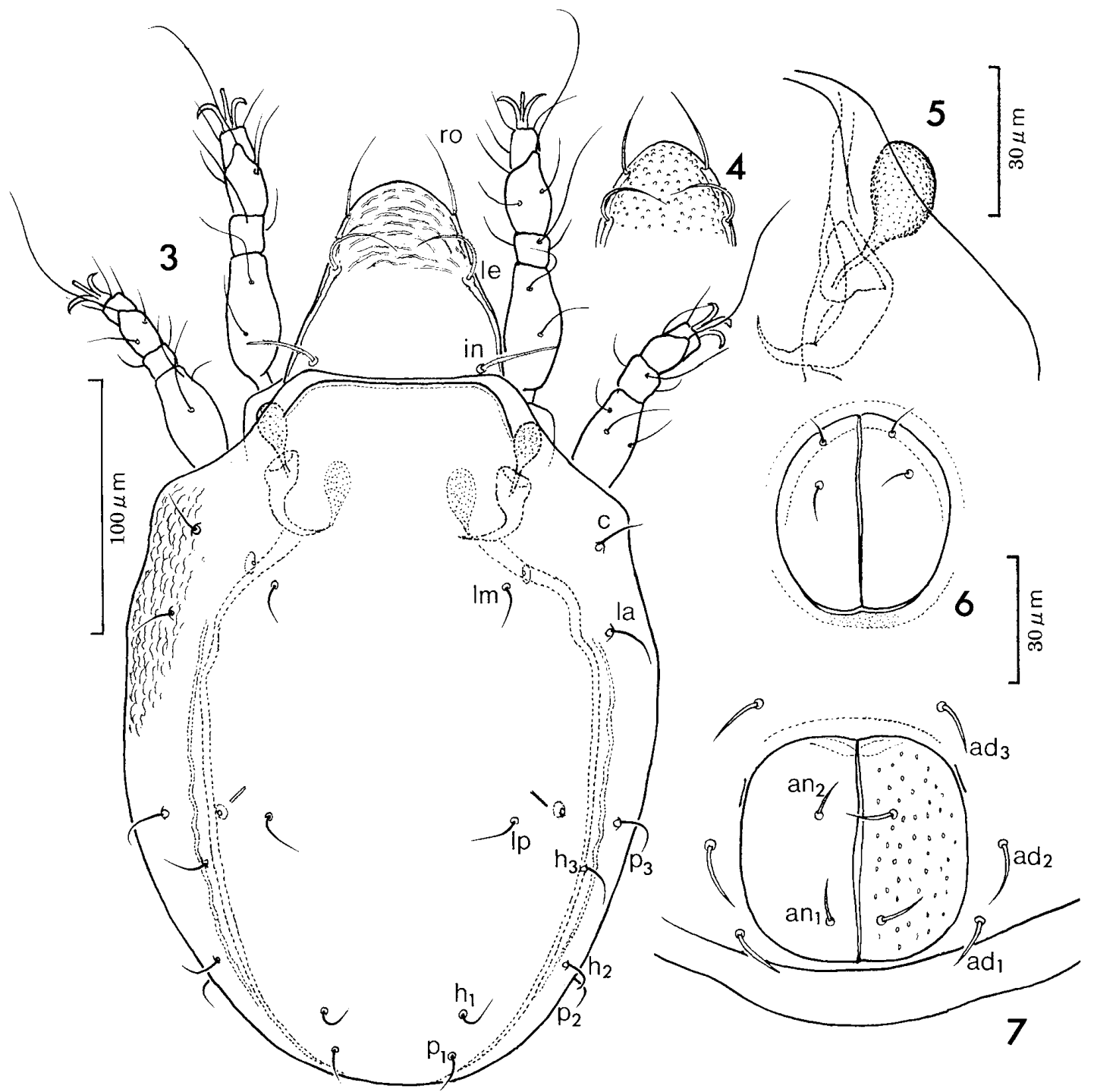

Figs 3-7. Oripoda obliqua sp. nov. 3, Dorsal side, holotype, female (NSMT-Ac 12038); 4, rostrum, paratype, male (NSMT-Ac 12039); 5, sensillus and bothridium, paratype, male (NSMTAc 12040); 6, 7, genital (6) and anal (7) apertures, paratype, female (NSMT-Ac 12047).

araucariae Pérez-Iñigo and Pérez-Iñigo, Jr., 1993. Among these species, the sensilli are covered completely by anterior expansion of notogaster in $O$. araucariae, mostly covered in the new species, and half-covered in $O$. anguina, while they are mostly or completely exposed in the remaining species. The rostral margin is almost straight in $O$. anguina, $O$. canagartnami, and $O$. magna, sinuous in $O$. cubana, concave in $O$. sumonyii and $O$. angolensis, and weakly arched in $O$. divergens and $O$. araucariae, while it is unique in being strongly arched in the new species. The interlamellar setae are very long (distinctly longer than setae $l e$ ) in $O$. canagartnami, O. cubana, O. sumonyii, and O. magna, while these setae are short in the new species, of nearly the same length as setae ro and $l e$. 
Truncopes moderatus variabilis subsp. nov.

(Figs 8-16)

Material examined. Holotype: female, NSMT-Ac 12050, Fuchu Shrine in Wakayama City, central Japan, 20 April 2007, coll. Y. Yamamoto from Quercus glauca. Paratypes: 1 male and 4 females, NSMT-Ac 12051-12055, same data as holotype; 2 males and 10 females, NSMT-Ac 12056-12062, Fuchu Shrine in Wakayama City, central Japan, 10 May 2007, coll. Y. Yamamoto from Camellia japonica.

Measurements (in $\mu \mathrm{m}$ ). Males (3 exs): body length 310-340 (mean 326), width 152-170 (mean 161). Females (14 exs): body length 412-475 (mean 444), width 152-170 (mean 161).

Description. Rostrum usually with a rounded projection. Prodorsal setae (ro,

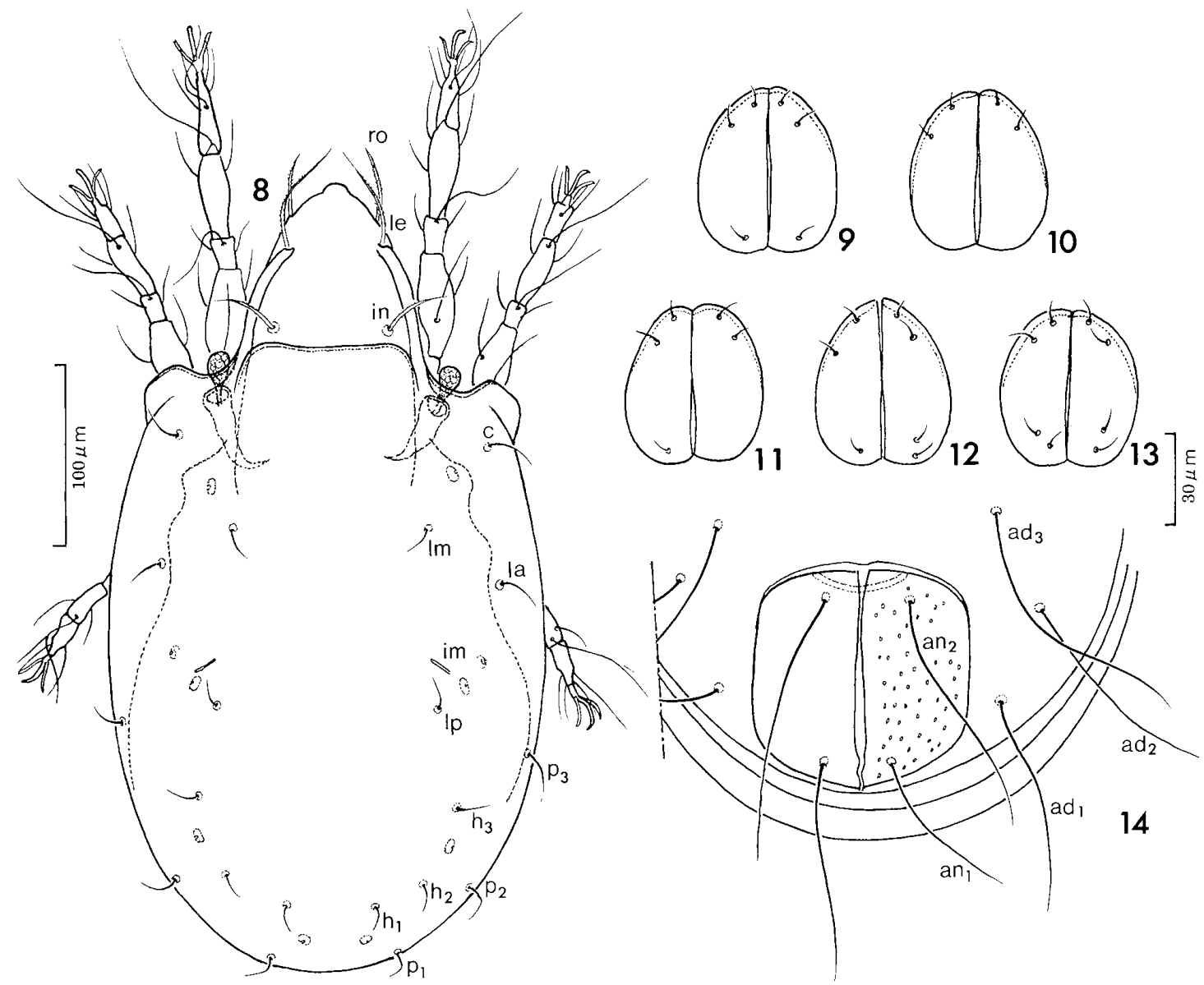

Figs 8-14. Truncopes moderatus variabilis subsp. nov. 8, Dorsal side; 9-13, genital apertures with various numbers of setae (9 representing normal condition); 14, anal region, showing anal and adanal setae. 8, 9, Holotype, female (NSMT-Ac 12050); 10, paratype, female (NSMT-Ac 12062); 11, paratype, female (NSMT-Ac 12053); 12, paratype, female (NSMT-Ac 12052); 13, 14, paratype, female (NSMT-Ac 12054). 
le, and in) thin and minutely barbed; seta in slightly longer than ro; seta le 1.2-1.4 $\times$ longer than in or ro. Lamella consisting of double ridges connecting to each other anteriorly at insertion pore of lamellar seta; thin ridge extending anteriorly from there to insertion pore of rostral seta. Sensillus bearing oval head, its basal third concealed beneath anterior part of notogaster. Prodorsal surface nearly smooth, without foveolae. Anterior margin of notogaster straight or slightly concave. Ante-

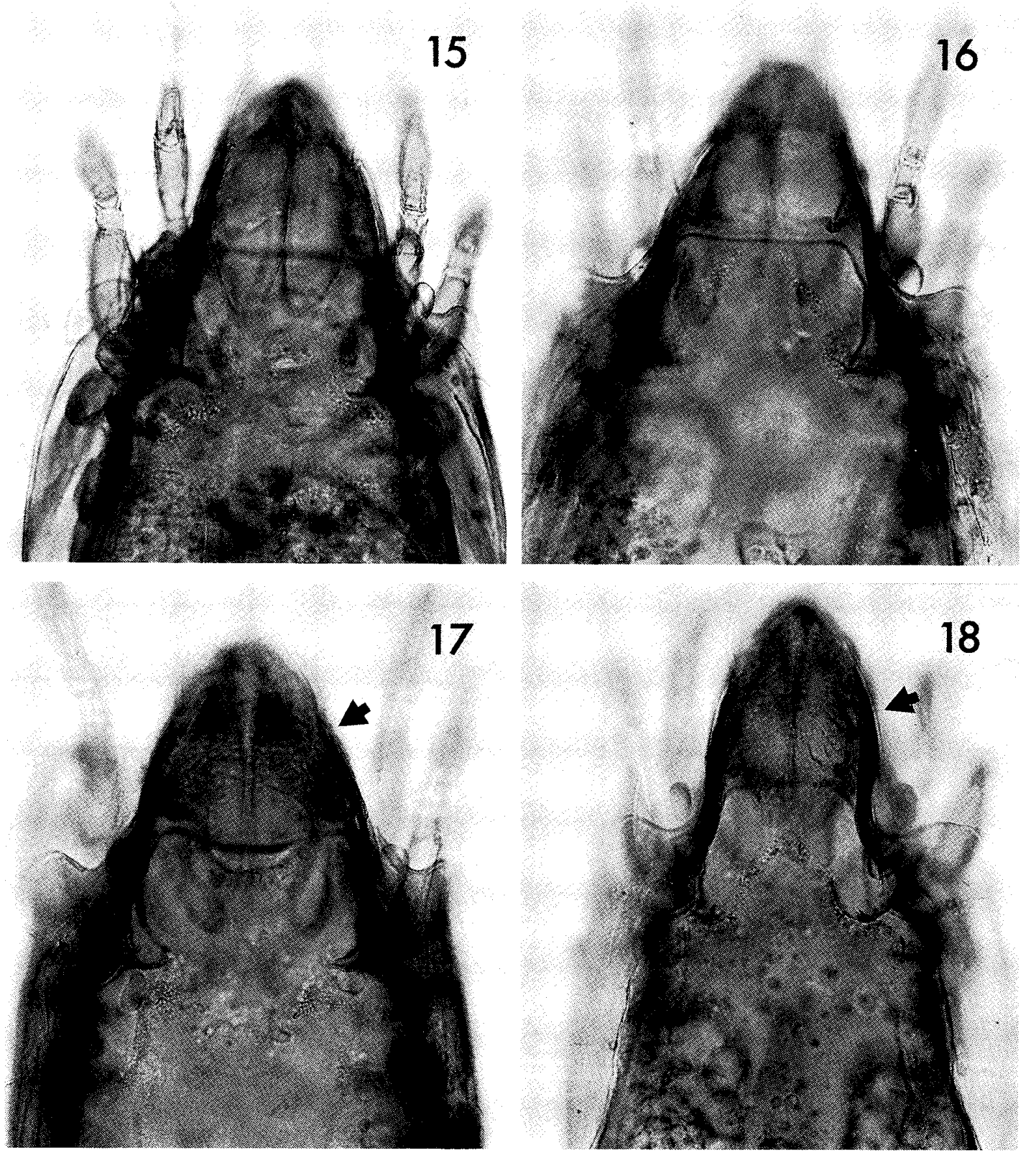

Figs 15-18. Anterior half of body in dorsal aspect, showing difference in surface structures of prodorsum. 15, 16, Truncopes moderatus variabilis subsp. nov. (smooth); 17, 18, Truncopes moderatus moderatus Aoki and Ohkubo, 1974 (foveolate, arrows). 15, Paratype, female (NSMT-Ac 12055); 16, holotype, female (NSMT-Ac 12050); 17, holotype, female (NSMT-Ac 8426); 18 , paratype, female (NSMT-Ac 8427). 
rior part of pteromorpha well projecting, sometimes with weakly angulate margin. Lateral margin of pteromorpha incurved, partly separating anterior projection from outline of body (Fig. 8). Ten pairs of notogastral setae thin and curved. Four pairs of sacculi small and oval; sacculus $S a$ of males $2.0-3.0 \times$ as large as other sacculi, while that of females almost equal in size to others. Length of genital opening $0.63-0.71 \times$ that of anal opening in both males and females; width of genital opening $0.52-0.55 \times$ that of anal opening in males and $0.62-0.69 \times$ in females, thus genital opening wider in females than in males. Number of genital setae basically 3 pairs (left-right): $3-3$ in 11 exs, but 3-2 in 3 exs, 2-3 in 1 ex., 2-2 in 1 ex., 4-3 in 1 ex., and 4-4 in $1 \mathrm{ex}$. Anal aperture with 2 pairs of long, whip-like setae; seta $a n_{1}$ inserted close to posterior end, and $a n_{2}$ close to anterior end, of anal plate. Three pairs of adanal setae also long and whip-like; seta $a d_{3}$ inserted at level anterior to anterior margin of anal aperture. One pair of aggenital setae somewhat longer than genital setae, their mutual distance little greater than width of genital opening. Surfaces of anal plates and ventral plate punctured with small foveolae.

All legs tridactyle, middle claw longer and thicker than lateral ones. Ventral keel of femur well developed only on leg II. Ventroproximal part of tibiae I-IV each with small and short projection.

Remarks. The new subspecies, Truncopes moderatus variabilis, is very similar to the nominotypical subspecies, T. moderatus moderatus Aoki and Ohkubo, 1974, which is known from the southern parts of Japan (Shikoku, Kyushu, and Yaku Island), but it is distinguishable from the latter in the following features (cf. Aoki and Ohkubo 1974): (1) the prodorsal surface of T. moderatus variabilis is almost smooth (Figs 15, 16), while that of T. moderatus moderatus is distinctly foveolate (Figs 17, 18 ); (2) the humeral projection of the new subspecies is half-way separated by the outline of the pteromorpha (not separated in $T$. moderatus moderatus); and (3) the number of genital setae is variable in the new subspecies, which often lacks a seta or has an additional seta on one or both sides (Figs 10, 11 and 12, 13, respectively) (always three pairs in T. moderatus moderatus).

\section{References}

Aoki, J. and Ohkubo, N. 1974. A proposal of new classification of the family Oripodidae (s. lat.), with description of new species. Bulletin of the National Science Museum, Tokyo 17: $117-147$.

Balogh, J. 1958. Lebensgemeinschaften der Landtiere. Verlag der Ungarischen Akademie der Wissenschaften, Budapest, 560 pp.

Balogh, J. and Balogh, P. 1992. The Oribatid Mites Genera of the World. Vol. 1. Hungarian Natural History Museum, Budapest, 263 pp.

Subias, L. S. 2004. Listado sistemático, sinonimico y biogeográfico de los acaros oribátidos (Acariformes, Oribatida) del mundo (1758-2002). Graellsia 60: 3-305. 